\title{
Enzymatic Polymerization of Dimethyl 2,5-Furandicarboxylate and Heteroatom Diamines
}

\author{
Dina Maniar, $^{\dagger}$ Katharina F. Hohmann, $^{\dagger, \dagger}$ Yi Jiang, $^{\dagger}$ Albert J. J. Woortman, ${ }^{\dagger}$ Jur van Dijken, $^{\dagger}$ \\ and Katja Loos*,† \\ ${ }^{\dagger}$ Macromolecular Chemistry \& New Polymeric Materials, Zernike Institute for Advanced Materials, University of Groningen, \\ Nijenborgh 4, 9747 AG, Groningen, The Netherlands \\ ${ }^{\ddagger}$ Institute for Organic Chemistry and Chemical Biology, Johann Wolfgang Goethe-University, Max-von-Laue-Straße 7, D-60438 \\ Frankfurt am Main, Germany
}

\section{Supporting Information}

ABSTRACT: Previously, we have synthesized a diverse range of 2,5furandicarboxylic acid (FDCA)-based semiaromatic polyamides via enzymatic polymerization. This novel class of polymers are biobased alternatives to polyphthalamides, which are petrol-based semiaromatic polyamides. From a commercial perspective, they have interesting properties as high-performance materials and engineering thermoplastics. It is even more appealing to explore novel FDCA-based polyamides with added functionality, for the development of sustainable functional materials. Here, a set of FDCA-based heteroatom polyamides have been successfully produced via Novozyme 435 (N435)-catalyzed polymerization of biobased dimethyl 2,5-furandicarboxylate with (potentially)heteroatom diamines, namely, 4,9-dioxa-1,12-dodecanediamine (DODA), diethylenetriamine, and 3,3-ethylenediiminopropylamine. We performed the enzymatic polymerization in solution and bulk. The latter approach is more sustainable and results in higher molecular weight products. Among the tested heteroatom diamines, N435 shows the highest catalytic activity toward DODA. Furthermore, we find that all obtained FDCA-based heteroatom polyamides are amorphous materials with a relatively high thermal stability. These heteroatom polyamides display a glass-transition temperature ranging from 41 to $107^{\circ} \mathrm{C}$.

\section{INTRODUCTION}

Most commonly, semiaromatic polyamides are used as highperformance materials and engineering thermoplastics. This is owned to their good mechanical properties, excellent chemical resistance, and other interesting features. ${ }^{1,2}$ These polymers have many applications in the automobile industry, electronic and electrical appliances, packaging, photovoltaic parts and panels, medical devices, and also for materials that are used for oil and gas extraction.

Currently, semiaromatic polyamides are mainly produced from fossil fuels. However, these resources are limited and are expected to be depleted within a few centuries. ${ }^{3-5}$ Generally, semiaromatic polyamides are obtained by polycondensation of aliphatic diamines with petrol-based terephthalic acid (TPA) and isophthalic acid, ${ }^{6,7}$ although the prevalent combination of aliphatic diamines and aromatic diacids gives access to a large range of semiaromatic polyamides with diverse properties. Using these compounds in polycondensation to obtain highmolecular-weight products at high conversion requires extreme condition and is energy-intensive. ${ }^{8-11}$

Recent research shows that 2,5-furandicarboxylic acid (FDCA) has been put forward as an alternative renewable building block to replace TPA. FDCA is a rigid difunctional

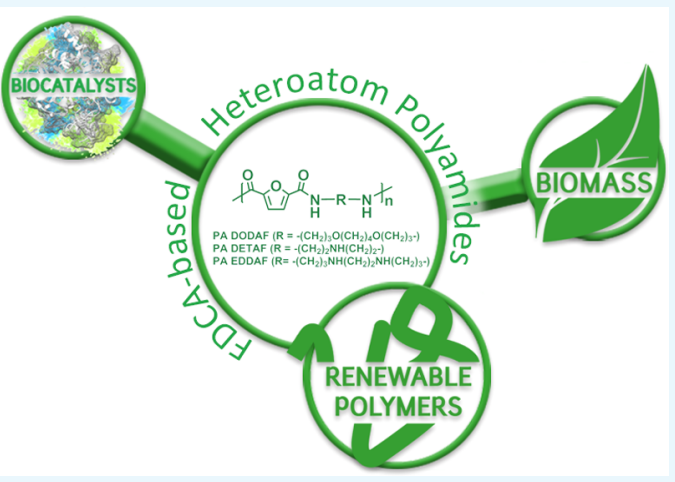

furan compound resembling TPA in structure, which is likely to play an important role in the construction of biobased polymer materials, ${ }^{12-15}$ for example, via polycondensation. ${ }^{14}$ FDCA can be directly generated by oxidation of 5(hydroxymethyl)furfural, which is easily prepared from widely available renewable C6 sugars or polysaccharides. ${ }^{16,17}$ In addition, the production of other heteroatom-containing chemicals from renewable resources (including heteroatom amines) is steadily under development. ${ }^{18}$ Previously, the polymerization of diverse furanic monomers has been reported, for example, the synthesis of furanic-aromatic polyamides from difuranic acid chloride and various difuranic diamines. ${ }^{19,20}$ FDCA-based polymers reportedly have better or similar thermal and mechanical properties compared to TPA-based polymers. ${ }^{15,21-27}$ Consequently, polyphthalamides (semiaromatic polyamides) can potentially be replaced by sustainable FDCA-based polyamides.

In general, living organisms synthesize macromolecules by in vivo enzyme-catalyzed polymerization. Mimicking such behav-

Received: May 23, 2018

Accepted: June 18, 2018

Published: June 28, 2018 
Scheme 1. Enzymatic Synthesis of FDCA-Based Heteroatom Polyamides via N435-Catalyzed Polycondensation of DMFDCA and Heteroatom Diamines in Solution or in Bulk

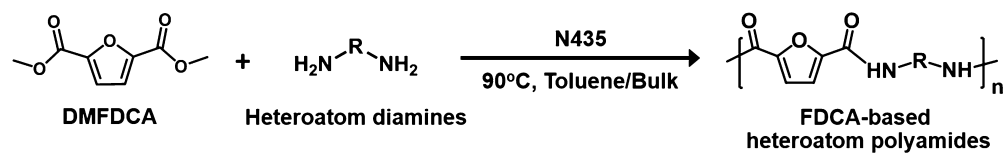

PA DODAF $\left(\mathrm{R}=-\left(\mathrm{CH}_{2}\right)_{3} \mathrm{O}\left(\mathrm{CH}_{2}\right)_{4} \mathrm{O}\left(\mathrm{CH}_{2}\right)_{3}-\right) ;$ PA DETAF $\left(\mathrm{R}=-\left(\mathrm{CH}_{2}\right)_{2} \mathrm{NH}\left(\mathrm{CH}_{2}\right)_{2}-\right) ;$ PA EDDAF $\left(\mathrm{R}=-\left(\mathrm{CH}_{2}\right)_{3} \mathrm{NH}\left(\mathrm{CH}_{2}\right)_{2} \mathrm{NH}\left(\mathrm{CH}_{2}\right)_{3}-\right)$

Table 1. Molecular Weight and Thermal Properties of the FDCA-Based Heteroatom Polyamides

\begin{tabular}{|c|c|c|c|c|c|c|c|c|c|}
\hline polymer & solvent & $\begin{array}{c}\text { vaccum } \\
(\mathrm{mm} \mathrm{Hg})\end{array}$ & $\bar{M}_{\mathrm{n}}^{b}\left(\mathrm{~g} \mathrm{~mol}^{-1}\right)$ & ${\overline{M_{\mathrm{W}}}}^{b}\left(\mathrm{~g} \mathrm{~mol}^{-1}\right)$ & $\bar{M}_{\mathrm{p}}^{b}\left(\mathrm{~g} \mathrm{~mol}^{-1}\right)$ & $\left(\overline{M_{\mathrm{W}}} / \overline{M_{\mathrm{n}}}\right)$ & $\begin{array}{c}\text { yield }^{d} \\
(\%)\end{array}$ & $\underset{\left({ }^{\circ} \mathrm{C}\right)}{T_{\mathrm{g}}^{e}}$ & $T_{\mathrm{d}}\left({ }^{\circ} \mathrm{C}\right)$ \\
\hline \multirow[t]{2}{*}{ PA DODAF } & toluene & atm & 6360 & 14930 & 14200 & 2.35 & 26 & 58 & $264^{f} ; 351^{h}$ \\
\hline & bulk & $30^{a}$ & 8030 & 16620 & 17000 & 2.07 & 37 & 44 & $297^{f} ; 432^{h}$ \\
\hline \multirow[t]{2}{*}{ PA DETAF } & toluene & atm & $c$ & $c$ & 3700 & $c$ & 71 & 107 & $204^{f} ; 292^{g} ; 361^{h}$ \\
\hline & bulk & $30^{a}$ & $c$ & $c$ & 5300 & $c$ & 93 & 93 & $202^{f} ; 288^{g} ; 358^{h}$ \\
\hline \multirow[t]{2}{*}{ PA EDDAF } & toluene & atm & $c$ & $c$ & 4800 & $c$ & 60 & 51 & $193^{f} ; 358^{h}$ \\
\hline & bulk & $30^{a}$ & $c$ & $c$ & 5300 & $c$ & 79 & 41 & $186^{f} ; 366^{h}$ \\
\hline
\end{tabular}

${ }^{a_{T}}$ The polymerization conditions used were stage-1: $80{ }^{\circ} \mathrm{C}, 2 \mathrm{~h}$, atm and stage-2: $80{ }^{\circ} \mathrm{C}, 70 \mathrm{~h}, 30 \mathrm{~mm} \mathrm{Hg} .{ }^{b}$ The number-average molecular weight $\left(\overline{M_{n}}\right)$, weight-average molecular weight $\left(\overline{M_{\mathrm{W}}}\right)$, peak molecular weight $\left(\overline{M_{\mathrm{p}}}\right)$, and dispersity $\left(\nexists, \overline{M_{\mathrm{W}}} / \overline{M_{\mathrm{n}}}\right)$ were determined by SEC using DMF/ $\mathrm{LiBr}$ as the eluent. ${ }^{c} \mathrm{Can}$ not be corrected: the signal is partly outside the polystyrene standard range. ${ }^{d}$ Isolated yield. ${ }^{e} T_{\mathrm{g}}$ (glass-transition temperature) was measured from the second DSC heating scan. ${ }^{f_{\text {Decomposition }}}$ temperature at $5 \%$ weight loss $\left(T_{\mathrm{d}-5 \%}\right)$. ${ }^{g}$ Decomposition temperature at $10 \%$ weight loss $\left(T_{\mathrm{d}-10 \%}\right) .{ }^{h}$ Temperature at the maximum rate of decomposition.

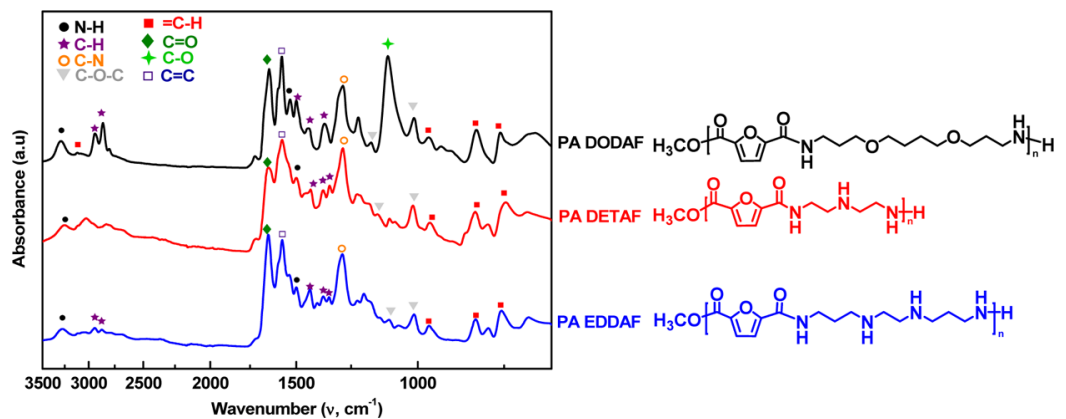

Figure 1. ATR-FTIR spectra of FDCA-based heteroatom polyamides produced via enzymatic polymerization in bulk.

ior in nature has let to in vitro enzymatic polymerization to be a well-known field, leading to a notable interest in the production of novel and commodity polymeric materials in a sustainable manner. ${ }^{28-31}$ Side reactions can be significantly inhibited by using enzymatic polymerization because of the high specificity of biocatalysts and mild reaction conditions. ${ }^{32}$ In the past decade, a vast array of polymer classes have been produced via enzymatic polymerization, such as polysaccharides, vinyl polymers, polyester, and polyamides. Hydrolase is among the most widely used biocatalyst for polymer synthesis. Hydrolases such as esterases, proteases, and lipases are popularly used in polyester synthesis. In addition, hydrolase can also catalyze the amide bond formation, making them good biocatalysis for polyamide synthesis. Currently, the most extensively studied enzymes in polyamide synthesis are lipases and protease. In our laboratory, various polyesters and polyamides are successfully synthesized via enzymatic polymerization, including furan-based polyesters and furan-based polyamides. $^{7,33-36}$

Although the use of enzymatic polymerization is being extensively studied, there is still a need for the further exploration of this method to be applied in the synthesis of various novel biobased polymers that are still not accessible via conventional methods, for example, functional FDCA polymers. Because of the additional functionality, new materials can be developed. Moreover, FDCA-based polymers, especially polyamides, have not been well explored up until now, and the knowledge of such polymers is barely based on limited studies.

The aim of the research is, therefore, to demonstrate the use of a bioderived furan monomer in combination with heteroatom-containing diamines via enzymatic polymerization, to synthesize biobased polyamides with added functionality. The resulting products will hereinafter be referred to as FDCAbased heteroatom polyamides. We performed the enzymatic synthesis both in solution and in bulk, and the latter approach adds more sustainability aspects to the final products. Moreover, we studied the thermal properties and crystallinity of these heteroatom polyamides and investigated the difference compared to polymers synthesized from dimethyl 2,5furandicarboxylate (DMFDCA) with linear aliphatic diamines.

\section{RESULTS AND DISCUSSION}

N435-Catalyzed Polycondensation of DMFDCA and Various Heteroatom Diamines via Solution and Bulk Polymerization. In this work, a series of FDCA-based heteroatom polyamides, namely, PA DODAF, PA DETAF, and PA EDDAF, were successfully synthesized via enzymatic polymerization (see Scheme 1). The enzymatic polycondensation was carried out in bulk and in solution at $90{ }^{\circ} \mathrm{C}$ using the biocatalyst N435. Biobased DMFDCA and three heteroatom 


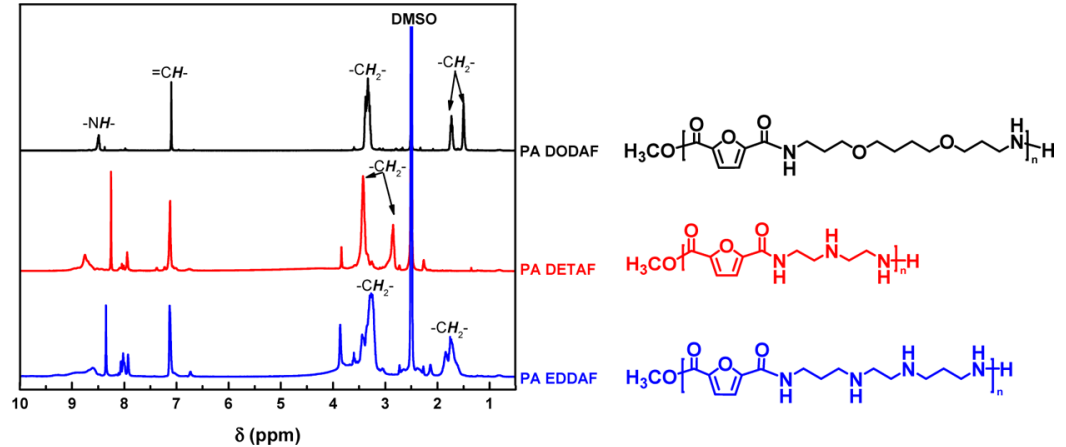

Figure 2. ${ }^{1} \mathrm{H}$ NMR spectra of FDCA-based heteroatom polyamides produced via enzymatic polymerization in bulk.

diamines were used as the monomer: 4,9-Dioxa-1,12dodecanediamine (DODA) with ether groups and diethylenetriamine (DETA) and 3,3-ethylenediiminopropylamine (EDDA) having secondary amine groups. The enzymatic polymerization results are summarized in Table 1 .

The obtained FDCA-based heteroatom polyamides chemical structures are confirmed by attenuated total reflectanceFourier transform infrared (ATR-FTIR) and NMR (see Figures 1 and 2, respectively). The Experimental Section described detailed NMR and IR assignments.

Influence of Diamines on Enzymatic Polymerization. FDCA-based heteroatom polyamides with relatively high molecular weight up to $14900 \mathrm{~g} / \mathrm{mol}$ were obtained by using DODA as a diamine monomer (Table 1). By changing to heteroatom diamines containing secondary amine groups (DETA and EDDA), the enzymatic polymerization resulted in lower molecular weight polyamides (see Figure S2). This indicated that N435 shows better catalytic activity toward DODA compared to that of DETA and EDDA. This result concur well with Schwab et al., ${ }^{37}$ in which they also demonstrate that the amide formation by Candida Antarctica lipase B (CALB) is preferable with DODA compared to that with DETA. However, we have to take into account the fact that reactivity of the diamines has a strong influence on molecular weights. In general, the reactivity of amines depends on both their basicity and nucleophilicity. The basicity increases with the number of the electron-donating groups that are linked to the amine functionality. The nucleophilicity is determined by several factors such as its charge, the nature of the chemical group present in or near the amine substituents, and the nature of the solvent used in the reaction. ${ }^{38}$

The enzymatic polymerization with DODA resulted in PA DODAF with the lowest isolation yield compared to the other two. Upon changing to diamines having secondary amine groups, the isolation yield increases to more than $\sim 50 \%$. This can be explained by the higher solubility of PA DODAF oligomers in the precipitant (THF). PA DODAF oligomers have a higher solubility in the THF compared to PA DETAF and PA EDDAF oligomers. During the purification steps, a higher amount of short chain oligomers were removed, thus resulting in lower yields. Another polymerization method or other suitable precipitants should be used to increase the reaction yield.short chain oligomers were removed, thus resulting in lower yields. Another polymerization method or other suitable precipitants should be used to increase the reaction yield.

Previously in our laboratory, different FDCA-based aromatic polyamides (see Scheme 2a) were successfully synthesized by
Scheme 2. Chemical Structures of (a) FDCA-Based Aromatic Polyamides (PAXF) and (b) FDCA-Based Heteroatom Polyamides

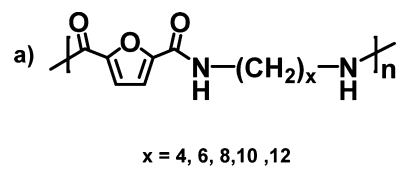

b)

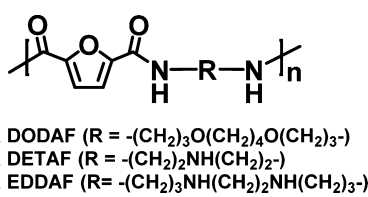

using N435 as a biocatalyst. ${ }^{33}$ FDCA-based aromatic polyamides with high weight-average molecular weight up to $48300 \mathrm{~g} \mathrm{~mol}^{-1}$ were successfully prepared. However, in this study, the enzymatic polymerization gave significantly lower molecular weight heteroatom counterparts. This may suggest that the tested heteroatom diamines (DODA, DETA, and EDDA) are less favored by CALB because of its ether or amine groups. This is in good agreement with our earlier findings, in which we also found that the enzymatic polymerization of polyester involving alkane- $\alpha, \omega$-aliphatic linear diols is more favored compared to diethylene glycol. ${ }^{35}$ Nevertheless, our results prove the substrate promiscuity of CALB as the biocatalyst.

Influence of the Enzymatic Polymerization Method on the Molecular Weights and Isolation Yields. Both the enzymatic polymerization in toluene and in bulk give FDCAbased heteroatom polyamide with comparable molecular weights, but in bulk, the molecular weights are higher. From this, we can conclude that the enzymatic polymerization in bulk is preferred. The high molecular weights in bulk polymerization could be attributed to the lower enzyme catalytic activity in the organic solvent: toluene. Toluene possesses a $\log P$ value of 2.73 , which is a suitable organic solvent for the lipase-catalyzed polymerization. However, the presence of toluene in the system changes the structure conformation of the enzyme and thus reduces its catalytic activity. ${ }^{39}$ On the other hand, in the solvent-free system, the enzyme retains its structure and thus shows a higher catalytic activity. Furthermore, we applied vacuum in the enzymatic polymerization in bulk where the elimination of the residual alcohol and water is facilitated.

The enzymatic polymerization in bulk resulted in FDCAbased heteroatom polyamides with higher isolation yields compared to that in toluene. This is quite reasonable due to the fact that the enzymatic polymerization in toluene gives lower molecular weight FDCA-based heteroatom polyamides.

Microstructures of the Obtained FDCA-Based Heteroatom Polyamides. The microstructures and end groups of the FDCA-based heteroatom polyamides were analyzed by 

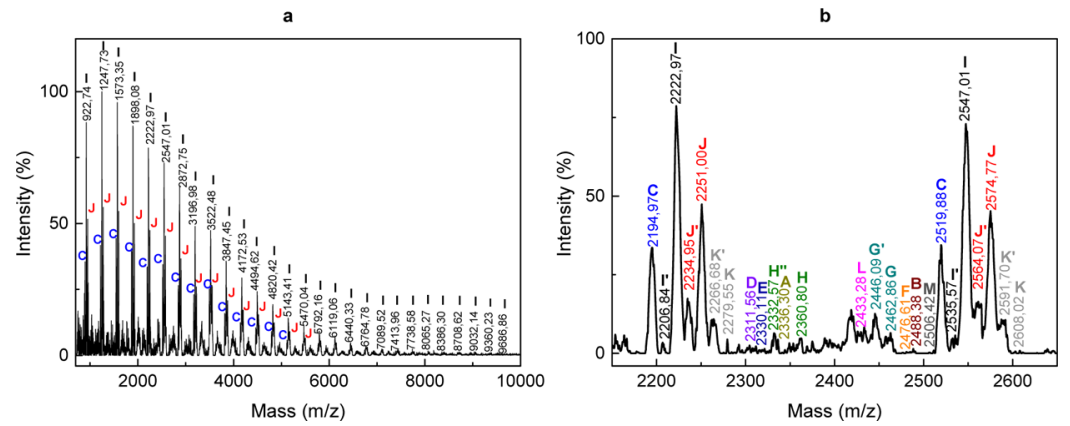

Figure 3. (a) MALDI-ToF MS spectrum of the obtained PA DODAF and (b) magnified part with detailed peak interpretation. A-H represent eight polyamide species ionized by $\mathrm{K}^{+}$. $\mathrm{G}^{\prime}$ represents the polyamides having the acid/acid end groups that are ionized by $\mathrm{Na}^{+} . \mathrm{H}^{\prime \prime}$ represents the polyamide having ester/amide end groups that are ionized by $\mathrm{H}^{+}$. $\mathrm{I}-\mathrm{M}$ represent five polyamide species fragment because of the fragmentation in the heteroatom bond. $\mathrm{I}^{\prime}-\mathrm{K}^{\prime}$ represent the polyamide species fragment that are ionized by $\mathrm{Na}^{+}$. PA DODAF was produced via enzymatic polymerization in bulk.

Table 2. MALDI-ToF MS Analysis: End Groups of the Obtained FDCA-Based Heteroatom Polyamides

\begin{tabular}{|c|c|c|c|}
\hline Entry & Polymer species & End groups & Remaining mass (amu) \\
\hline A & & Ester/Amine & 32.03 \\
\hline B & & Ester/Ester & 184.15 \\
\hline $\mathrm{C}$ & 11 & Amine/Amine & $\begin{array}{r}\mathrm{R}=-\left(\mathrm{CH}_{2}\right)_{3}-\mathrm{O}-\left(\mathrm{CH}_{2}\right)_{4}-\mathrm{O}-\left(\mathrm{CH}_{2}\right)_{3}-: 204.19 \\
\mathrm{R}=-\left(\mathrm{CH}_{2}\right)_{2}-\mathrm{NH}-\left(\mathrm{CH}_{2}\right)_{2}-: 103.11 \\
\mathrm{R}=-\left(\mathrm{CH}_{2}\right)_{3}-\mathrm{NH}-\left(\mathrm{CH}_{2}\right)_{2}-\mathrm{NH}-\left(\mathrm{CH}_{2}\right)_{3}-: 174.29\end{array}$ \\
\hline $\mathrm{D}$ & & Cyclic & 0 \\
\hline $\mathrm{E}$ & & Acid/Amine & 18.02 \\
\hline $\mathrm{F}$ & & Ester/Acid & 170.12 \\
\hline G & $\mathrm{H}-\mathrm{R}-\mathrm{N}^{\prime}$ & Acid/Acid & 156.09 \\
\hline $\mathrm{H}$ & 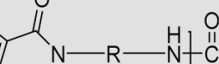 & Ester/Amide & 60.05 \\
\hline
\end{tabular}

matrix-assisted laser desorption/ionization-time of flight mass spectrometry (MALDI-ToF MS). Figure 3 shows the representative MALDI spectra.

Similarly as in our previous study, when we used monoatomic aliphatic diamines, eight different polyamide species were identified (see Table 2). They were terminated by ester/ester, amine/amine, ester/amine, acid/amine, acid/acid, ester/amide, ester/acid, and cyclic polyamides (without end groups). However, in this work, additional end groups are identified. The heteroatom bond in the amine end group can easily be cleaved off during the ionization of the molecules in the MALDI-ToF measurement, resulting in new fragmentation 

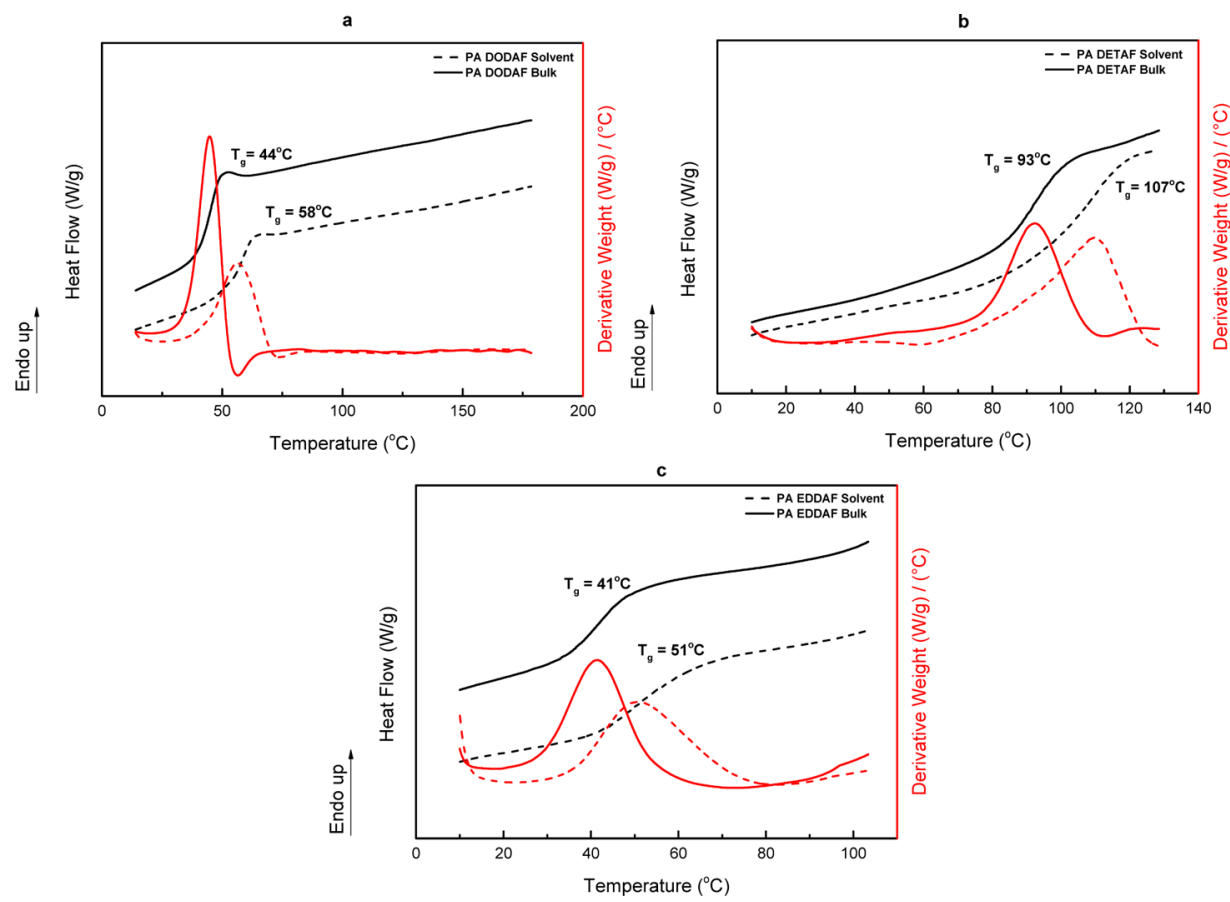

Figure 4. DSC second heating curves of the obtained FDCA-based heteroatom polyamides: (a) PA DODAF, (b) PA DETAF, and (c) EDDAF.
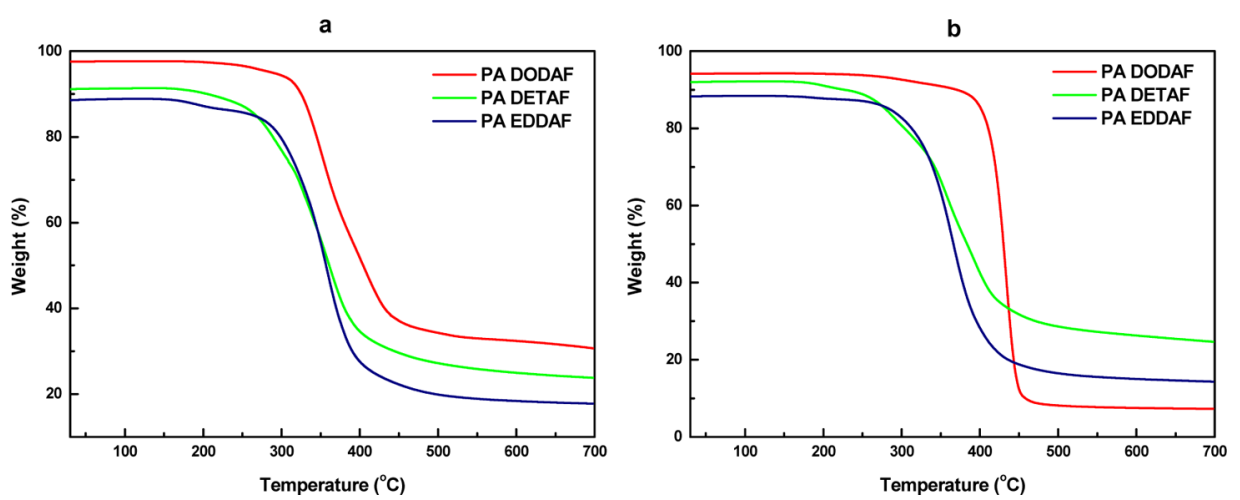

Figure 5. TGA traces of the obtained FDCA-based heteroatom polyamides: (a) enzymatic polymerization in solution and (b) in bulk.

patterns. Therefore, additional peaks are observed. For example, in the MALDI-ToF spectrum of PA DODAF, the peaks assigning to the additional end groups are marked as peaks I and J (see Figure 3 and Table S1-S3), indicating that the amine (DODA) end group of PA DODAF undergoes fragmentation in $\mathrm{C}-\alpha$ of the ether bond during MALDI-ToF measurements.

As previously reported by our group, the acid end group is formed because during the polymerization, the esters were catalytically hydrolyzed by N435. ${ }^{71,33}$ The formation of amide end groups occurred because of the reaction between amine groups and formic acid that we use at the purification step. $^{11}$

Crystallinity and Thermal Properties of the Obtained FDCA-Based Heteroatom Polyamides. The thermal behavior of the tested FDCA-based heteroatom polyamides was analyzed by differential scanning calorimetry (DSC). No melting and crystallization peaks were observed. This indicated that the obtained FDCA-based heteroatom polyamides are amorphous materials. As confirmed by the wide-angle X-ray diffraction (WAXD) measurements, no reflection peaks but only broad halo appeared (Figure S8).
The glass-transition temperature $\left(T_{\mathrm{g}}\right)$ of the obtained FDCA-based heteroatom polyamides is presented in Table 1 and Figure 4. The $T_{\mathrm{g}}$ was ranging from 41 to $107{ }^{\circ} \mathrm{C}$. PA DETAF showed the highest $T_{g}$ of $107{ }^{\circ} \mathrm{C}$. This can be explained by two facts. First, the repeating unit of PA DETAF is most rigid because of its shortest chain length. Second, the intermolecular hydrogen bond density in PA DETAF is higher due to the secondary amine groups. Moreover, the $T_{\mathrm{g}}$ of PA EDDAF approaches that of PA DODAF, even though the molecular weight of PA EDDAF is much lower. This can also be explained by the higher intermolecular hydrogen bond density in PA EDDAF. We also noticed that the $T_{\mathrm{g}}$ of FDCAbased heteroatom polyamides from enzymatic polymerization in bulk is lower, despite having higher molecular weight. This could be elucidated by the varied composition of the end groups generated from different synthetic approaches.

The $T_{\mathrm{g}}$ of the synthesized FDCA-based heteroatom polyamides decreases as the chain length of the heteroatom aliphatic diamine units increases. These results also agreed well with our previous results reported in the literature, ${ }^{33}$ which indicated that the $T_{\mathrm{g}}$ of semiaromatic polyamides decreased, 
whereas the chain length of the aliphatic diamine units increased.

The thermal stability of the tested FDCA-based heteroatom polyamides was determined by thermal gravimetric analysis (TGA). Figure 5 shows the TGA curves of the FDCA-based heteroatom polyamides. The temperature at $5 \%$ weight loss $\left(T_{\mathrm{d}-5 \%}\right)$ of all FDCA-based heteroatom polyamides was around 186-297 ${ }^{\circ} \mathrm{C}$. The temperature of maximal rate of decomposition $\left(T_{\mathrm{d}}\right)$ of all FDCA-based heteroatom polyamides was ranging from 351 to $432{ }^{\circ} \mathrm{C}$. In addition, we also observe $10 \%$ weight loss step in PA DETAF at temperature around 288$292{ }^{\circ} \mathrm{C}$. The temperature at the maximum rate of decomposition can mostly associate with the thermal cleavage of the amide bonds in the polymer backbones. However, to obtain additional information for understanding the thermal degradation mechanism steps, further analysis using TGA-GC/ MS coupling measurements is needed in the future. Considering their high decomposition temperature, all FDCA-based heteroatom polyamides have a very wide processing window.

\section{CONCLUSIONS}

We demonstrate that enzymatic catalysis is a robust pathway toward the synthesis of FDCA-based heteroatom polyamides. As confirmed by ${ }^{1} \mathrm{H}$ NMR and ATR-FTIR analysis, a series of FDCA-based heteroatom polyamides are successfully synthesized, with a $\overline{M_{\mathrm{W}}}$ of up to $16620 \mathrm{~g} / \mathrm{mol}$. We found that N435 shows the highest catalytic activity toward DODA, a diamine having ether groups, compared to the other two with secondary amines. Additionally, we found that enzymatic polymerization in bulk is more preferred. Furthermore, MALDI-ToF MS results indicated that no polyamide species can be assigned to the byproducts from undesirable side reaction.

All obtained FDCA-based heteroatom polyamides are amorphous materials with relatively high thermal stability. TGA analysis results show that all obtained FDCA-based heteroatom polyamides possess a $T_{\mathrm{d}-5 \%}$ and $T_{\mathrm{d}-\max }$ at around 186-297 and 351-432 ${ }^{\circ} \mathrm{C}$, respectively. Moreover, these heteroatom polyamides possess a glass-transition temperature at around $41-107{ }^{\circ} \mathrm{C}$. Because of the polymer chain rigidity, tested FDCA-based heteroatom polyamides having shorter diamine units generally possess higher glass-transition temperature.

In the future research, it will be of great interest to optimize reaction parameters to facilitate the enzymatic polymerization. Furthermore, we are aiming to thoroughly understand the enzymatic polymerization mechanism; thus, we can design a greener and more efficient pathway toward diverse biobased polymers.

\section{EXPERIMENTAL SECTION}

Materials. Novozym 435 [N435, Candida antartica lipase B (CALB) immobilized on acrylic resin, $5000+\mathrm{U} / \mathrm{g}$ ], 4,9-dioxa1,12-dodecanediamine (DODA, 99\%), DETA (reagent plus, 99\%), 1,2-bis(3-aminopropylamino) ethane (EDDA, technical grade, 94\%), toluene (anhydrous, 99, 8\%), formic acid (puriss, $98+\%)$, molecular sieves (4 ̊)), dimethyl sulfoxide- $d_{6}$ (DMSO$d_{6}, 99,5$ atom $\% \mathrm{D}$ ), and potassium trifluoroacetate (KTFA, 98\%) were purchased from Sigma-Aldrich. Dimethyl 2,5furandicarboxylate (DMFDCA, 97\%) was purchased from Fluorochem UK. 1,1,1,3,3,3-hexafluoro-2-propanol (HFIP,
99\%) was purchased from TCI Europe. Dithranol (98+\%) was purchased from Fluka. Tertrahydrofuran (THF, stabilized with BHT, pro analyze) was purchased from Boom BV. 2,5Dihydroxybenzoic acid (DHB, 98-100\%) was purchased from ThermoFisher scientific.

N435 was predried as reported previously, ${ }^{40}$ and the molecular sieves were preactivated at $200{ }^{\circ} \mathrm{C}$ in vacuo. All of the other chemicals were used without further purification.

Procedure for the N435-Catalyzed Solution Polymerization of DMFDCA with Various Heteroatom Diamines. Predried N435 (20 wt \% in relation to the total amount of the monomer) and preactivated molecular sieves (200 wt \%) were placed in a $25 \mathrm{~mL}$ round-bottle flask under a nitrogen environment. Subsequently, DMFDCA (5.000 mmol), diamines $(5.000 \mathrm{mmol})$, and anhydrous toluene $(500 \mathrm{wt} \%)$ were added into the flask. The flask was placed in an oil bath, and the reaction mixture was magnetically stirred under atmospheric pressure at $90{ }^{\circ} \mathrm{C}$ for $72 \mathrm{~h}$. After that, formic acid (15 $\mathrm{mL}$ ) was added to dissolve the products and then the solution was filtrated (folded filter type 15 Munktell $240 \mathrm{~mm}$ ) to remove N435 and molecular sieves. N435, molecular sieves, and filter paper were washed three times using formic acid (10 $\mathrm{mL}$ ). All of the obtained solutions were then combined and concentrated by a rotary evaporator at $40{ }^{\circ} \mathrm{C}$ under reduced pressure of 20-40 mbar. The concentrated solution was poured in an excess amount of THF. The solution with the precipitated products was then stored for several hours at -20 ${ }^{\circ} \mathrm{C}$. Subsequently, they were isolated via centrifugation $(30$ min, $4500 \mathrm{rpm}, 4{ }^{\circ} \mathrm{C}$ in Thermo/Heraeus Labofuge $400 \mathrm{R}$ ). The obtained crude products were dissolved by a small amount of formic acid and then added dropwise into THF. The final products were collected via centrifugation following the same procedure mentioned above and dried in vacuo at $40{ }^{\circ} \mathrm{C}$ for 3 days. Finally, they were stored in vacuo at room temperature prior to analysis.

Procedure for the N435-Catalyzed Bulk Polymerization of DMFDCA with Various Heteroatom Diamines. DMFDCA (5.000 mmol, $0.9208 \mathrm{~g})$, diamines $(5.000 \mathrm{mmol}$, $1.0216 \mathrm{~g})$, preactivated molecular sieves (200 wt \%), and predried N435 (20 wt \% in relation to the total amount of the monomer) were added into a $25 \mathrm{~mL}$ round-bottle flask. The reaction mixture was magnetically stirred at $90{ }^{\circ} \mathrm{C}$ under atmospheric pressure for $2 \mathrm{~h}$, followed by applying $30 \mathrm{~mm} \mathrm{Hg}$ pressure for $70 \mathrm{~h}$. After that, the obtained products were purified according to the same procedure as described above. Finally, the products were stored in vacuo at room temperature before analysis.

Poly(4,9-Dioxa-1,12-dodecamethylene furanamide) (PA DODAF). ${ }^{1} \mathrm{H}$ NMR (400 MHz, DMSO- $d_{6}, \delta$, ppm): $8.49(1 \mathrm{H}$, $\mathrm{m},-\mathrm{NH}-\mathrm{CO}-$, from DODA), $7.10(2 \mathrm{H}, \mathrm{s},=\mathrm{CH}-$, furan $)$, 3.38-3.30 (4H, $12 \mathrm{H}$, overlap multiplet, $-\mathrm{NH}-\mathrm{CH}_{2}-,-\mathrm{O}-$ $\mathrm{CH}_{2}-$, from DODA), $1.73\left(4 \mathrm{H}, \mathrm{m},-\mathrm{NH}-\mathrm{CH}_{2}-\mathrm{CH}_{2}-\mathrm{CH}_{2}-\right.$ $\mathrm{O}-$, from DODA), $1.50\left(4 \mathrm{H}, \mathrm{s},-\mathrm{O}-\mathrm{CH}_{2}-\mathrm{CH}_{2}-\mathrm{O}-\right.$, from DODA); ${ }^{13} \mathrm{C}$ NMR (300 MHz, DMSO- $\left.d_{6}, \delta, \mathrm{ppm}\right): 157.69$ (-CO-NH-, from DMFDCA), 148.67 (-NH-CO$\mathrm{C}(\mathrm{O})=\mathrm{CH}-$, from DMFDCA $), 114.69(=\mathrm{CH}-$, from DMFDCA), 70.36 (-O- $\mathrm{CH}_{2}-\mathrm{CH}_{2}-$, from DODA), 68.16 (-O-CH $\mathrm{CH}_{2}-\mathrm{CH}_{2}-\mathrm{CH}_{2}-\mathrm{NH}-\mathrm{CO}-$, from DODA), 36.42 $\left(-\mathrm{CH}_{2}-\mathrm{NH}-\mathrm{CO}-\right.$, from DODA $), 29.94\left(-\mathrm{CH}_{2}-\mathrm{CH}_{2}-\right.$ $\mathrm{NH}-\mathrm{CO}-$,from DODA $), 26.43\left(-\mathrm{O}-\mathrm{CH}_{2}-\mathrm{CH}_{2}-\right.$, from DODA).

Poly(3-Aza-1,5-pentamethylene furanamide) (PA DETAF). ${ }^{1} \mathrm{H}$ NMR $\left(400 \mathrm{MHz}, \mathrm{DMSO}-d_{6}, \delta, \mathrm{ppm}\right): 8.25(1 \mathrm{H}, \mathrm{m}, \mathrm{NH}-$ 
CO-, from DETA), 7.12 (2H, s, =CH-, furan), $3.43(4 \mathrm{H}, \mathrm{m}$, $-\mathrm{CO}-\mathrm{NH}-\mathrm{CH}_{2}-$, from DETA), $2.85\left(4 \mathrm{H}, \mathrm{s},-\mathrm{NH}-\mathrm{CH}_{2}-\right.$, from DETA); ${ }^{13} \mathrm{C}$ NMR (400 MHz, DMSO- $\left.d_{6}, \delta, \mathrm{ppm}\right)$ : 157.62 (-CO-NH-, from DMFDCA), 148.06 (-NH-CO$\mathrm{C}(\mathrm{O})=\mathrm{CH}-$, from DMFDCA $), 114.57$ (= $\mathrm{CH}-$, from DMFDCA), 47.29 (- $\mathrm{CH}_{2}-\mathrm{NH}-$, from DETA), 36.88 ( $-\mathrm{NH}-\mathrm{CO}-\mathrm{CH}_{2}-$, from DETA), $150.28(\mathrm{C}=\mathrm{O}$, end groups from DMFDCA), $119.26(=\mathrm{CH}-$, end groups from DMFDCA), 52.21 ( $-\mathrm{OCH}_{3}$, end groups from DMFDCA).

Poly(4,7-Diaza-1,10-decamethylene furanamide) (PA EDDAF). ${ }^{1} \mathrm{H}$ NMR (400 MHz, DMSO- $\left.d_{6}, \delta, \mathrm{ppm}\right): 8.35$ $(1 \mathrm{H}, \mathrm{m},-\mathrm{NH}-\mathrm{CO}-$, from EDDA), $7.13(2 \mathrm{H}, \mathrm{s},=\mathrm{CH}-$, furan $), 3.29-3,25(4 \mathrm{H}, 8 \mathrm{H}$, overlap multiplet, $-\mathrm{CO}-\mathrm{NH}-$ $\mathrm{CH}_{2}-,-\mathrm{NH}-\mathrm{CH}_{2}-$, from EDDA), $1.76(4 \mathrm{H}, \mathrm{m},-\mathrm{NH}-$ $\mathrm{CH}_{2}-\mathrm{CH}_{2}-$, from EDDA); ${ }^{13} \mathrm{C}$ NMR $\left(400 \mathrm{MHz}\right.$, DMSO- $d_{6}$, $\delta, \mathrm{ppm}): 157.38$ (-CO-NH-, from DMFDCA), 148.15 $(-\mathrm{NH}-\mathrm{CO}-\mathrm{C}(\mathrm{O})=\mathrm{CH}-$, from DMFDCA $), 114.38$ (= $\mathrm{CH}-$, from DMFDCA), $48.63\left(-\mathrm{NH}-\mathrm{CH}_{2}-\mathrm{CH}_{2}-\mathrm{NH}-\right.$, from $\mathrm{EDDA}), 44.6\left(-\mathrm{CO}-\mathrm{NH}-\mathrm{CH}_{2}-\mathrm{CH}_{2}-\mathrm{CH}_{2}-\mathrm{NH}-\right.$, from $\mathrm{EDDA}), 36.37$ (- $\mathrm{CO}-\mathrm{NH}-\mathrm{CH}_{2}-$, from $\left.\mathrm{EDDA}\right)$, 27.18 (-CO-NH$-\mathrm{CH}_{2}-\mathrm{CH}_{2}-$, from EDDA).

Furanic-aliphatic heteroatom polyamides $\left(\nu, \mathrm{cm}^{-1}\right): 3251-$ $3290(\mathrm{~N}-\mathrm{H}$ stretching vibrations); 3101-3114 (=C-H stretching vibrations of the furan ring); 2935-2944, 28312873 (asymmetric and symmetric $\mathrm{C}-\mathrm{H}$ stretching vibrations); 1643-1646 ( $\mathrm{C}=\mathrm{O}$ stretching vibrations); 1571-1573 (aromatic $\mathrm{C}=\mathrm{C}$ bending vibrations); $1500-1533$ ( $\mathrm{N}-\mathrm{H}$ bending vibrations); 1429-1500, 1369-1440 ( $\mathrm{C}-\mathrm{H}$ deformation and wagging vibrations); $1342-1365$ ( $\mathrm{C}-\mathrm{H}$ rocking vibrations); 1286-1288 ( $\mathrm{C}-\mathrm{N}$ stretching vibrations); 1105 (C-O-C asymmetric stretching vibrations, DODA); 1099-1168, 10121016 ( $=\mathrm{C}-\mathrm{O}-\mathrm{C}=$ ring vibrations, furan ring); 962-966, 821-825, 744-759 (= $\mathrm{C}-\mathrm{H}$ out-of-plane deformation vibrations, furan ring).

Instrumental Methods. ${ }^{1} \mathrm{H}$ NMR spectra were recorded on a Varian VXR Spectrometer $\left({ }^{1} \mathrm{H}: 400 ;{ }^{13} \mathrm{C} 300 \mathrm{MHz}\right)$, using DMSO- $d_{6}$ as the solvent. Chemical shifts $(\delta)$ are reported in parts per million (ppm), whereas the chemical shifts were referenced to the resonances of the residual solvent or tetramethylsilane.

ATR-FTIR spectra were recorded on a Bruker VERTEX 70 spectrometer in the range of $4000-400 \mathrm{~cm}^{-1}$, with 16 scans for each sample at a nominal resolution of $4 \mathrm{~cm}^{-1}$ using a diamond single reflection ATR.

Size exclusion chromatography (SEC) was performed in DMF (containing $0.01 \mathrm{M} \mathrm{LiBr}$ ) on Viscotek GPCmax equipped with model 302 TDA detectors, two columns (Agilent Technologies-PolarGel-L and M, $8 \mu \mathrm{m} 30 \mathrm{~cm}$ ) at a

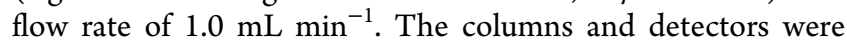
held at $50{ }^{\circ} \mathrm{C}$. Data acquisition and calculations were performed using Viscotek OmniSec software version 5.0. Molecular weights were determined based on a conventional calibration curve generated from narrow dispersity polystyrene standards (Agilent and PSS, $\overline{M_{\mathrm{W}}}=550-1190000 \mathrm{~g} / \mathrm{mol}$ ). The samples were filtered over a $0.2 \mu \mathrm{m}$ PTFE filter prior to injection.

Thermal transitions of the obtained polyamides were measured by DSC on TA-Instruments Discovery DSC 2500. The samples were scanned by heating-cooling-heating scans with heating-cooling rates of $10{ }^{\circ} \mathrm{C} / \mathrm{min}$. Tzero aluminium pinhole hermetic pans were used for all of the DSC measurements.
Thermal stability of the obtained polyamides was characterized by TGA on TA-Instruments Discovery TGA 5500 on an open pan under a nitrogen environment. The scan rate was $10{ }^{\circ} \mathrm{C} / \mathrm{min}$. To remove the remaining water and solvents in the polymer, the tested sample was first heated up to $150{ }^{\circ} \mathrm{C}$ and then maintained at this temperature for $30 \mathrm{~min}$ before the standard TGA measurement.

MALDI-ToF MS measurements were performed on a Biosystems Voyager-DE PRO spectrometer in the positive ionization and the linear mode using an accelerating voltage of $25 \mathrm{kV}$. The grid voltage, guide wire voltage, and delay time were optimized for each spectrum to achieve the best signal-tonoise ratio. PA DODAF and PA DETAF samples were prepared using $20 \mathrm{mg} / \mathrm{mL}$ matrix solution of dithranol in HFIP. Polymer sample solution in HFIP $(1-2 \mathrm{mg} / \mathrm{mL})$, potassium trifluoroacetate in HFIP (KTFA, $5 \mathrm{mg} / \mathrm{mL}$ ), and dithranol $(20 \mathrm{mg} / \mathrm{mL})$ were premixed in a ratio of $5: 1: 5$. After that, the resulting mixture $(0,2-0,6 \mu \mathrm{L})$ was hand-spotted on a MALDI target plate and left to dry. PA EDDAF samples were prepared using $40 \mathrm{mg} / \mathrm{mL}$ matrix solution of $\mathrm{DHB}$ in $70 / 30$ acetonitrile/water with $0.1 \%$ TFA. Typically, a $1: 2$ mixture of polymer sample solution in HFIP $(1-2 \mathrm{mg} / \mathrm{mL})$ was mixed with the DHB matrix solution. Subsequently, the mixture was hand-spotted on the MALDI target plate and left to dry. Polyamide species having different end groups were determined by the following equation: $M_{\mathrm{P}}=M_{\mathrm{EG}}+(n \times$ $\left.M_{\mathrm{RU}}\right)+M_{\mathrm{K}}{ }^{+}$, where $M_{\mathrm{P}}$ is the molecular mass of a polyamide species, $M_{\mathrm{EG}}$ is the molecular mass of the end groups, $n$ is the number of the repeating units, $M_{\mathrm{RU}}$ is the molecular mass of the repeating units, and $\mathrm{M}_{\mathrm{K}}{ }^{+}$is the molecular mass of the potassium cation.

WAXD spectra were recorded at room temperature using a Bruker D8 Advance diffractometer $(\mathrm{Cu} \mathrm{K} \alpha$ radiation, $\lambda=$ $0.1542 \mathrm{~nm})$ in the angular range of $5-50^{\circ}(2 \theta)$.

\section{ASSOCIATED CONTENT}

\section{Supporting Information}

The Supporting Information is available free of charge on the ACS Publications website at DOI: 10.1021/acsomega.8b01106.

MALDI-TOF analysis: additional end groups of the obtained FDCA-based heteroatom polyamides, ${ }^{13} \mathrm{C}$ NMR spectra of FDCA-based heteroatom polyamides produced via enzymatic polymerization in bulk, SEC elution curves of the obtained FDCA-based heteroatom polyamides, and MALDI-ToF MS spectra of the obtained FDCA-based heteroatom polyamides with detailed peak interpretation (PDF)

\section{AUTHOR INFORMATION}

\section{Corresponding Author}

*E-mail: k.u.loos@rug.nl. Phone: +31-50 3636867 (K.L.). ORCID $\odot$

Katja Loos: 0000-0002-4613-1159

Notes

The authors declare no competing financial interest.

\section{ACKNOWLEDGMENTS}

D.M. thanks the financial support from the Indonesian Endowment Fund for Education (Lembaga Pengelola Dana Pendidikan LPDP) 


\section{ABBREVIATIONS}

FDCA, 2,5-furandicarboxylic acid; N435, Novozyme 435; DMFDCA, dimethyl 2,5-furandicarboxylate; DODA, 4,9dioxa-1,12-dodecanediamine; DETA, diethylenetriamine; EDDA, 3,3-ethylenediiminopropylamine; TPA, terephthalic acid; IPA, isophthalic acid; HMF, 5-(hydroxymethyl)furfural; PA DODAF, poly(4,9-dioxa-1,12-dodecamethylene furanamide); PA DETAF, poly(3-aza-1,5-pentamethylene furanamide); PA EDDAF, poly(4,7-diaza-1,10-decamethylene furanamide); ATR-FTIR, attenuated total reflection-Fourier transform infrared; ${ }^{1} \mathrm{H}$ NMR, proton nuclear magnetic resonance; SEC, size exclusion chromatography; DSC, differential scanning calorimetry; TGA, thermal gravimetric analysis; MALDI-ToF MS, matrix-assisted laser desorption/ionizationtime of flight mass spectrometry; WAXD, wide-angle X-ray diffraction

\section{REFERENCES}

(1) Glasscock, D.; Atolino, W.; Kozielski, G.; Martens, M. High Performance Polyamides Fulfill Demanding Requirements for Automotive Thermal Management Components; DuPont Engineering Polymers, 2008.

(2) Marchildon, K. Polyamides - Still Strong After Seventy Years. Macromol. React. Eng. 2011, 5, 22-54.

(3) Williams, C.; Hillmyer, M. Polymers from Renewable Resources: A Perspective for a Special Issue of Polymer Reviews. Polym. Rev. 2008, 48, 1-10.

(4) van Putten, R.-J.; van der Waal, J. C.; de Jong, E.; Rasrendra, C. B.; Heeres, H. J.; de Vries, J. G. Hydroxymethylfurfural, A Versatile Platform Chemical Made from Renewable Resources. Chem. Rev. 2013, 113, 1499-1597.

(5) Rass-Hansen, J.; Falsig, H.; Jørgensen, B.; Christensen, C. H. Bioethanol: fuel or feedstock? J. Chem. Technol. Biotechnol. 2007, 82, 329-333.

(6) Weber, J. N. Polyamides. Kirk-Othmer Encyclopedia of Chemical Technology, 4th ed.; John Wiley \& Sons, Inc: 2011; Vol. 19, pp 454518.

(7) Jiang, Y.; Maniar, D.; Woortman, A. J. J.; Alberda van Ekenstein, G. O. R.; Loos, K. Enzymatic Polymerization of Furan-2,5Dicarboxylic Acid-Based Furanic-Aliphatic Polyamides as Sustainable Alternatives to Polyphthalamides. Biomacromolecules 2015, 16, 36743685.

(8) Poojari, Y.; Clarson, S. J. Lipase-Catalyzed Synthesis and Properties of Silicone Aromatic Polyesters and Silicone Aromatic Polyamides. Macromolecules 2010, 43, 4616-4622.

(9) Poulhès, F.; Mouysset, D.; Gil, G.; Bertrand, M. P.; Gastaldi, S. CAL-B catalyzed synthesis of chiral polyamides. Tetrahedron: Asymmetry 2012, 23, 867-875.

(10) Stavila, E.; Arsyi, R. Z.; Petrovic, D. M.; Loos, K. Fusarium solani pisi cutinase-catalyzed synthesis of polyamides. Eur. Polym. J. 2013, 49, 834-842.

(11) Stavila, E.; Alberda van Ekenstein, G. O. R.; Loos, K. EnzymeCatalyzed Synthesis of Aliphatic-Aromatic Oligoamides. Biomacromolecules 2013, 14, 1600-1606.

(12) Sousa, A. F.; Matos, M.; Freire, C. S. R.; Silvestre, A. J. D.; Coelho, J. F. J. New copolyesters derived from terephthalic and 2,5furandicarboxylic acids: A step forward in the development of biobased polyesters. Polymer 2013, 54, 513-519.

(13) Gandini, A. The irruption of polymers from renewable resources on the scene of macromolecular science and technology. Green Chem. 2011, 13, 1061-1083.

(14) Gandini, A.; Lacerda, T. M.; Carvalho, A. J. F.; Trovatti, E. Progress of Polymers from Renewable Resources: Furans, Vegetable Oils, and Polysaccharides. Chem. Rev. 2016, 116, 1637-1669.

(15) de Jong, E.; Dam, M. A.; Sipos, L.; Gruter, G.-J. M. Furandicarboxylic Acid (FDCA), A Versatile Building Block for a Very
Interesting Class of Polyesters; American Chemical Society, 2012; Vol. 1105, pp $1-13$.

(16) Delidovich, I.; Hausoul, P. J. C.; Deng, L.; Pfützenreuter, R.; Rose, M.; Palkovits, R. Alternative Monomers Based on Lignocellulose and Their Use for Polymer Production. Chem. Rev. 2016, 116, $1540-1599$.

(17) Vilela, C.; Sousa, A. F.; Fonseca, A. C.; Serra, A. C.; Coelho, J. F. J.; Freire, C. S. R.; Silvestre, A. J. D. The quest for sustainable polyesters - insights into the future. Polym. Chem. 2014, 5, 31193141.

(18) Hülsey, M. J.; Yang, H.; Yan, N. Sustainable Routes for the Synthesis of Renewable Heteroatom-Containing Chemicals. ACS Sustainable Chem. Eng. 2018, 6, 5694-5707.

(19) Abid, S.; El Gharbi, R.; Gandini, A. Polyamides incorporating furan moieties. 5. Synthesis and characterisation of furan-aromatic homologues. Polymer 2004, 45, 5793-5801.

(20) Gharbi, S.; Gandini, A. Synthese de nouveaux polyamides entierement furaniques. J. Soc. Chim. Tunis. 2004, 6, 17-26.

(21) Gandini, A.; Silvestre, A. J. D.; Neto, C. P.; Sousa, A. F.; Gomes, M. The furan counterpart of poly(ethylene terephthalate): An alternative material based on renewable resources. Polym. Chem. 2009, 47, 295-298.

(22) Deng, J.; Liu, X.; Li, C.; Jiang, Y.; Zhu, J. Synthesis and properties of a bio-based epoxy resin from 2,5-furandicarboxylic acid (FDCA). RSC Adv. 2015, 5, 15930-15939.

(23) Gubbels, E.; Jasinska-Walc, L.; Koning, C. E. Synthesis and Characterization of Novel Renewable Polyesters Based on 2,5Furandicarboxylic Acid and 2,3-Butanediol. J. Polym. Sci., Part A: Polym. Chem. 2013, 51, 890-898.

(24) Moreau, C.; Belgacem, M. N.; Gandini, A. Recent catalytic advances in the chemistry of substituted furans from carbohydrates and in the ensuing polymers. Top. Catal. 2004, 27, 11-30.

(25) Du, P.; Wu, M.; Liu, X.; Zheng, Z.; Wang, X.; Sun, P.; Joncheray, T.; Zhang, Y. Synthesis of linear polyurethane bearing pendant furan and cross-linked healable polyurethane containing Diels-Alder bonds. New J. Chem. 2014, 38, 770-776.

(26) Cousin, T.; Galy, J.; Rousseau, A.; Dupuy, J. Synthesis and properties of polyamides from 2,5-furandicarboxylic acid. J. Appl. Polym. Sci. 2018, 135, 45901.

(27) Ma, K.; Chen, G.; Wang, W.; Zhang, A.; Zhong, Y.; Zhang, Y.; Fang, X. Partially bio-based aromatic polyimides derived from 2,5furandicarboxylic acid with high thermal and mechanical properties. J. Polym. Sci., Part A: Polym. Chem. 2018, 56, 1058-1066.

(28) Gross, R. A.; Kumar, A.; Kalra, B. Polymer synthesis by in vitro enzyme catalysis. Chem. Rev. 2001, 101, 2097-2124.

(29) Kobayashi, S.; Makino, A. Enzymatic polymer synthesis: an opportunity for green polymer chemistry. Chem. Rev. 2009, 109, $5288-5353$

(30) Gross, R. A.; Ganesh, M.; Lu, W. Enzyme-catalysis breathes new life into polyester condensation polymerizations. Trends Biotechnol. 2010, 28, 435-443.

(31) Jiang, Y.; Loos, K. Enzymatic Synthesis of Biobased Polyesters and Polyamides. Polymers 2016, 8, 243.

(32) Semlitsch, S. Building Blocks for Polymer Synthesis by Enzymatic Catalysis. Ph.D. Dissertation, KTH Royal Institute of Technology, 2017.

(33) Jiang, Y.; Maniar, D.; Woortman, A. J. J.; Loos, K. Enzymatic synthesis of 2,5-furandicarboxylic acid-based semi-aromatic polyamides: enzymatic polymerization kinetics, effect of diamine chain length and thermal properties. RSC Adv. 2016, 6, 67941-67953.

(34) Jiang, Y.; Woortman, A.; van Ekenstein, G.; Loos, K. EnzymeCatalyzed Synthesis of Unsaturated Aliphatic Polyesters Based on Green Monomers from Renewable Resources. Biomolecules 2013, 3, 461-480.

(35) Jiang, Y.; Woortman, A. J. J.; Alberda van Ekenstein, G. O. R.; Loos, K. A biocatalytic approach towards sustainable furanic-aliphatic polyesters. Polym. Chem. 2015, 6, 5198-5211.

(36) Jiang, Y.; Woortman, A. J. J.; Alberda van Ekenstein, G. O. R.; Petrović, D. M.; Loos, K. Enzymatic Synthesis of Biobased Polyesters 
Using 2,5-Bis(hydroxymethyl)furan as the Building Block. Biomacromolecules 2014, 15, 2482-2493.

(37) Schwab, L. W. Polyamide Synthesis by Hydrolases. Ph.D. Dissertation, University of Groningen, Groningen, 2010.

(38) Froidevaux, V.; Negrell, C.; Caillol, S.; Pascault, J.-P.; Boutevin, B. Biobased Amines: From Synthesis to Polymers; Present and Future. Chem. Rev. 2016, 116, 14181-14224.

(39) Wang, S.; Meng, X.; Zhou, H.; Liu, Y.; Secundo, F.; Liu, Y. Enzyme Stability and Activity in Non-Aqueous Reaction Systems: A Mini Review. Catalysts 2016, 6, 32.

(40) Jiang, Y.; van Ekenstein, G. O. R. A.; Woortman, A. J. J.; Loos, K. Fully Biobased Unsaturated Aliphatic Polyesters from Renewable Resources: Enzymatic Synthesis, Characterization, and Properties. Macromol. Chem. Phys. 2014, 215, 2185-2197. 